\title{
The Role of Civil Society in Indonesia for Global Humanitarian Narratives in Digitalization Era
}

\author{
Muhammad Faizal Alfian ${ }^{1}$, Robetmi Jumpakita Pinem ${ }^{2}$ \\ \{mfaizalalfian@gmail.com ${ }^{1}$, robetmi@lecturer.undip.ac.id² \\ Universitas Diponegoro, Indonesia ${ }^{1,2}$
}

\begin{abstract}
In recent years, civil society as IR actors has actively challenged the dynamics of international politics. This paper aims to explore the role of Civil Society in Indonesia, engagement, and advocacy in world politics, particularly in the Human Rights Issue. While globalization has raised numerous network civil society, Information Communication Advancement enhanced the power and influence of civil society engagement in world politics generating the online activism movement. We use several concepts such as cyberactivism and Transnational Advocacy Network to explain the role and engagement of civil society. In the human rights issue, the Civil Society in Indonesia has been involved in online activities including social media communities, and social movements of collective actions. These actions form functions of civil society as Watchdogs: hold institutions to account, promote transparency and accountability; Advocate: increase awareness of social problems and challenges and support change; Representative: gives power to marginalized or underrepresented voices; Citizen Champions: encourage citizen involvement and support citizens' rights; Solidarity supporter: promoting the fundamental and universality of human values.
\end{abstract}

Keywords: Civil Society in Indonesia, Humanitarian, Digitalization

\section{Introduction}

In the last two decades, the actors in IR literature have made several influences in the form of global politics. In the current context of international political dynamics, civil society has been considered as a pivotal actor among others actors such as the state, private corporations, international organizations, and media organizations.

Information and Communication Technology (ICT) creating space for civil society participating in global issues that support the development of cross-border community networks. Schawb [1] in his article The Future Role of Civil Society argue the ICT has opened up space for civil society activities gaining power and significant influence in both cyber and physical environments, and it is possible to create social networks across nations. The internet and other advanced technologies penetrate beyond the social activities of society to create more space for freedom of information. Social media platforms are becoming a prevalent activity and generate new forms of society. Social media platforms increase social interaction dynamically and contribute shared value among people around the world. Social media users create content to get social capital from their social networks to achieve their goals [2]. As a result, social interactions trough would be creating networks that connecting common ideas of people and share group identities across geographic boundaries. 
There are several articles concern about the role of civil society in shaping the humanitarian narratives and turning to humanitarian responses [3][4][5]. Mitoma [3] argue civil society organizations as networks of intellectual and political power identify as source emerging of the human rights issue. Similar to the research, [6] examined the role of civil society networks in Sudan in peacebuilding. Sperfeldt and Oeung [7] also concern about the role of civil society participating in the Khmer Rouge trials. Some of these studies prove that civil society is playing an active role in the humanitarian response.

This article focuses on civil society actors who organized positively to respond to the global humanitarian problems and to pressure stakeholders including international organizations to solve humanitarian problems. This participation and activities form the networks of society in Indonesia. We also distinguish civil society in general from community organizations to identify the roles of each actor in the global humanitarian.

\section{Method}

This research is a qualitative research with a descriptive approach. The qualitative approach means that the data obtained is generalized in order to obtain answers to the problem formulation. To observe the role of civil society in global humanitarian issues in the digitalization era, the authors use data analytics where could be found from trends and mentions on websites and social media using app.brand24.com. Data analytics would be related to keywords from the internet/website regarding global humanitarian issues. This study uses secondary data collection methods through content data posted on the internet and social media related to global humanitarian issues. The data consists of narrative content, accounts that focus on discussing global issues, of course narrative or these accounts have a basis of ideas / ideas, values, or identity. The data is collected, selected, categorized, interpreted, it can be described using the existing frame of mind. In explaining the role and movement of civil society we use the Cluster Approach to define the divisions among agency and define agency roles and responsibilities. The cluster approach aims to make the humanitarian community more structured, accountable, and professional, thus civil society is able to become partners with government and international institutions or local authorities where they operated [8].

\subsection{Civil Society Network Concept}

Civil society is defined as an entity formed from groups based on identity, ideas, and values that shared common goals, and mutual understanding among individuals. Civil society is outside of the family, government, and markets where people interact to advance their interests. An important element of this definition is a group of people who share common identities, values, thoughts, and interests [9]. Civil society actors become different from political actors that potentially enhance democracy in global governance. Civil society represents the common aspirations of participating in international policy-making processes that should make political decisions more acceptable or legitimate in society at large.

According to Marchetti [10], the presence of civil society in international political developments is recognized as two different roles: (1) civil society organizations have played a key role in the promotion of democracy through the affirmation of human rights; (2) civil society organizations also play a role in serving the community. This assumption is also supported by Barnes [11] who argues Civil society is being able to respond in conflict and resolution from injustice situations to narrative for preventing violence, creating conditions conducive and 
ensuring consolidation into peace talks. Based on this assumption, the role of civil society could be operating in humanitarian principles that create pressure on policymakers at the domestic level or promoting a humanitarian issue that appeared in the international sphere. Civil society involvement increases the set of competing policy ideas seeking the best possible outcome for the international community. They also play a role because of the lack of pressure on local and global policymakers. On various issues, the national and international governments tend to be passive in making progress in addressing a problem. Civil society can move and pressure so that stakeholders get community support.

\section{Result and Discussion}

\subsection{Civil Society Network Concept}

The development of ICT enhances the capacity of people who are connected to the internet on a daily to express their interests. This development expanded from communication media to all domains of social life in global and local networks, at the same time resulting in a massive pattern of change [12]. In Indonesia, this pattern has observed with the increasing number of internet users and technological advances developments have significant influence during the transition to democracy in Indonesia. Hill and Sen [13] explain the central role of communication technology in the transformation from authoritarian to democracy in 1998, while Lim [14] states that technology is a political and economic vehicle in the transition to Indonesian democracy. We argue that information technology becomes an economic and political instrument supporting this major transformation.

In 2008, the internet needs to be increased with the development of access to the internet in educational institutions in Indonesia [15]. Until 2014, internet users are dominated in political communication which affects political contestation until the next political year in 2019 . According to a survey from Asosiasi Penyelenggara Jasa Internet Indonesia [16], internet usage in Indonesia reached $64.8 \%$ or 171 million users in 2018 , it is more than half of Indonesia people have connected through the internet. In addition, internet users tend to increase along with the emergence of COVID-19 Pandemic at the end of 2019.

ICT and the development of the internet and community communication space become a two-edged sword that has negative and positive impacts. Hui [15] research explores the increase in internet activity in Indonesia shows the Jemaah Islamiyah (JI) terrorist network is ordered to create negative content to provoke the public. Internet for some radical organization networks is medium for spreading their propaganda. On the positive side, information technology is a challenge for the advancement of Indonesian civil society, with increasing social awareness in the form of mutual solidarity regarding the principles of humanity. In this condition, the response to globalization is the adaptation in this dynamic of change.

\subsection{Indonesian Civil Society in Global Humanitarian Issues}

The global level of humanitarian crisis impacts Indonesia, there are more than 13.800 refugees and asylum seekers in Indonesia [17]. According to the Indonesian Ministry of Foreign Affairs, the estimations for the number of asylum seekers who transit and stop in Indonesia would continue to increase every year. This number of refugees occurred from the Rohingya people who faced systematic discrimination, statelessness, and targeted violence in Rakhine State, Myanmar. The Rohingya refugees where it is becoming a common issue for civil society 
in South and South-east Asia. Until 2020, hashtags included \#RohingyaMuslims with 12.432, \#RohingyaRefugees with 9,649 hashtags from any social media, across the globe with largely from Muslim majority countries including Indonesia, Bangladesh dan Malaysia.

Table 1. Rohingya Refugees Issue in Internet Platform from 3 August-1 September 2020

\begin{tabular}{|c|l|c|c|}
\hline No. & \multicolumn{1}{|c|}{ Country } & Mentions & Social Media Reach \\
\hline 1 & Indonesia & 860 & 11421 \\
\hline 2 & Vietnam & 36 & 0 \\
\hline 3 & India & 35 & 0 \\
\hline 4 & Italy & 30 & 0 \\
\hline 5 & Georgia & 16 & 0 \\
\hline
\end{tabular}

Source: Processed by authors data analytics from app.brand24.com.

Data analytics show the Indonesian people have been mention Rohingya and the humanitarian crisis 860 times on the internet with social media reach of 11.421 (the social media reach is calculated from re-tweet, response, and like that showing interested in the issue). This data particularly show Indonesian civil society has more concern to humanitarian issue and action and it could be multiplied by time resulting spread of information not only at the national level but also at the global level. Global problems only matter if they reflect deep feelings and needs for the social conditions of society [18]. Strategies for emotional responses have been used in the marketing of humanitarian aid organizations since the 1980s through a variety of media formats [18]. Therefore, the information would create more space for people to concern the Rohingya issue and shared their common understanding of humanitarian issues. According to Peberdy and Jara [4] research claims civil society playing a pivotal role in ensuring the health, safety, and well-being of refugees. Simultaneously at the domestic level, civil society generating support and demand in decision-making in foreign policy that persuades the government to take an action for the humanitarian problems.

Several organizations have to facilitate a forum for community aspirations to accommodate ideas and provide pressure on the Indonesian government for protecting refugees. Indonesian Civil Society Association for refugee right protection (SUAKA) is an organization that is the focal point for advocating several humanitarian issues. The leader of SUAKA:

"With the existence of several organizations that support the development of these issues, discourse on global issues able to put pressure on the Indonesian government in formulating policies on refugees. In the end, the role of NGOs can become a bridge between civil society and stakeholders that aspirations could be absorbed into a policy" [19].

Indonesian civil society also put their attention on the Middle East crisis. In 2020, the dominant narrative for Palestine is of particular concern to social media users with \#palestinewillbefree with 99,209 hashtags, while the attention of solidarity actions to the humanitarian crisis in Palestine reaches \#palestinesolidaritycampaing with 1,286 hashtags, and \#palestinesolidarityday with 1,137 hashtags. This humanitarian crisis also attracted the attention of civil society in Indonesia to produce a form of humanitarian action, especially in the case of the Palestinian humanitarian crisis commonly form global solidarity.

Table 2. Palestine Crisis Issue in Internet Platform from 3 August - 1 September 2020

\begin{tabular}{|c|l|c|c|}
\hline No. & \multicolumn{1}{|c|}{ Country } & Mentions & Social Media Reach \\
\hline 1 & Indonesia & 26 & 27271 \\
\hline 2 & Vietnam & 13 & 56 \\
\hline
\end{tabular}




\begin{tabular}{|c|l|c|c|}
\hline 3 & India & 9 & 296 \\
\hline 4 & Italy & 6 & 242 \\
\hline 5 & Georgia & 4 & 0 \\
\hline
\end{tabular}

Source: Processed by authors data analytics from app.brand24.com.

Between 3 August until 1 September 2020, Palestine's humanitarian issue has been mentioned 26 times with social media reach 27.271 by Indonesian People. That is indicating the civil society also has concern for the Palestine crisis. This narrative brings other responses just not spreading the information, some civil society group creating the humanitarian actions facilitating health, school, and another form of humanitarian aid. This action has provided by some group of civil society such The Indonesian humanitarian agency Aksi Cepat Tanggap (ACT) who provide assistance boats for fishermen in Gaza. Another humanitarian act shows form of food provided by the Indonesian Humanitarian Center in Gaza who distributed 250 Tons of food aid. This type of engagement contributes to solidarity actions organized and turn to increase the ongoing flow of aid to the Middle East.

\subsection{Humanitarian Responses and the Role Civil Society}

Based on the Rohingya refugee and Palestine freedom, it emphasizes the important role of civil society in shaping global humanitarian issues. The ICT supports the role of civil society in narrative spread through internet/ social media, especially in addressing humanitarian violence, displacement, and various forms of oppression in global discourse. Civil society is to be an agent in encouraging citizen involvement and supporting the fulfillment of their rights, at the same time they are able to shape institutions accountable, promote government transparency and accountability, and raise awareness of humanitarian problems that occurred. World Economic Forum [1] summarizes the civil society role in technological developments:

a. Demanding institutions accountable, promoting government transparency (Watchdog);

b. Raising awareness of social problems and challenges and support change (Advocate);

c. A representative for marginalized people (representative);

d. Encouraging citizen involvement and supporting human rights (Citizen champion);

e. Promoting fundamental and universal values (Solidarity supporter);

f. Creating norms that shape the activities of actors (Definer of standards).

The ICT development is developed as a channel for society to express their ideas and narrative that it could affect the development of international politics. In the Rohingya refugees' case, civil society obtains the power to shape the global humanitarian narrative. This power to form narrative and get more attention in humanitarian discourse. Community organizations and NGOs occurred as a bridge to deliver the issue and absorbed into demand and support that produces a foreign policy. Civil society activities in social media/internet generate the narrative of humanitarian issues, social media to be an alternative to compile aspirations that turning to shared understanding and solidarity.

To explain the relationship between this discourse and the humanitarian response of society, we use a framework for action by Cox [20] who describes the structures, powers, and actors in international politics. He suggests a simple framework for identifying three determinants in the configuration of the structure, namely idea, material capabilities, and institutions [21]. (1) Material capability is the productive and destructive potential for actors in political interactions. Community interaction is a type of material ability to generate political power. (2) Ideas related to the notion of social relations, or could be defined as political interactions in the international community which tend to perpetuate habits and expectations of 
behavior. (3) The institution is a power relationship which is material power and ideas. Material capabilities and ideas determine political interactions between actors such as war, negotiation, conflict, cooperation, or alliances. This configuration creates a gradual transformation of international politics based on state capabilities such as arms and industry. Based on the explanation we describe the relationship between power and civil society in figure 1 .

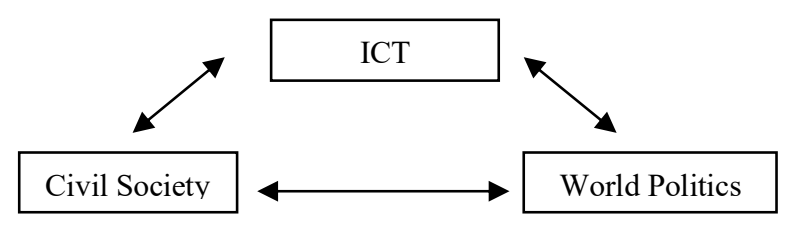

Fig. 1. Framework of Action Civil Society and ICT.

Based on this basis, information becomes the material ability of civil society whose basis of thought is created from the ideas and norms values that exist in society, which then makes civil society form perceptions about political phenomena. This capability can put pressure on policymakers such as international organizations and countries as policymakers. ICT supports various humanitarian responses for instance providing services to accommodate basic needs such as education, health, food, and security; implementing disaster management, preparedness, and emergency response (Service Provider) and provides education, training, and other capacity-building (Capacity builder) [1]. These activities potentially provide civil society to be dominant actors in human rights. Civil society as an agent has ideas, identities, and norms that influence the structure of international. Civil society institute ideational spreading information and forming a common understanding. Meanwhile, organizations, NGOs, civil society movement become agents actualizing ideas and creating and formulating programs/ planning for humanitarian actions and humanitarian assistance.

Table 3. The role of civil society and NGO in Humanitarian Issue

\begin{tabular}{|l|l|}
\hline \multicolumn{1}{|c|}{ Civil Society } & \multicolumn{1}{|c|}{ NGO/Civil Society Organization } \\
\hline $\begin{array}{l}\text { Primary role: } \\
\text { hpread information and demands on } \\
\text { humanitarian issues }\end{array}$ & $\begin{array}{l}\text { Primary role: } \\
\text { Develop humanitarian action and } \\
\text { humanitarian aid strategies. }\end{array}$ \\
\hline Demanding institutional responsibility & $\begin{array}{l}\text { Providing services for the basic needs of } \\
\text { society }\end{array}$ \\
\hline Raising awareness of social problems & $\begin{array}{l}\text { Capacity builders provide training, } \\
\text { education }\end{array}$ \\
\hline A representative for marginalized people & Applying disaster management \\
\hline $\begin{array}{l}\text { And early warning system, encouraging } \\
\text { citizen involvement and supporting human } \\
\text { rights }\end{array}$ & $\begin{array}{l}\text { Implementing disaster management and } \\
\text { emergency response }\end{array}$ \\
\hline $\begin{array}{l}\text { Creating norms that shape the activities of } \\
\text { actors }\end{array}$ & $\begin{array}{l}\text { To accommodate civil society ideas and } \\
\text { value. }\end{array}$ \\
\hline
\end{tabular}

The development of technology enhances the ability and capability of civil society to play an important role in humanitarian issues. The use of social media in general facilitates political engagement and political information, arranges discussion, and maintaining social networks [22]. Psychologically, civil society could be defended and support victims of crimes against 
humanity. On the other hand, the use of the internet provides opportunities for civil society to mobilize collective action and mobilize the flow of resources to established non-governmental organizations (NGOs) and aid agencies and lead to the formation of new citizen initiatives and mobilization of people and voluntary [23]. According to Lewis [5], humanitarian responses take different forms and operate on different scales in challenging dominant institutions or media that tend to provide certain responses.

According to Vegh [24], the Internet functions as an alternative source of news and information. Independent individuals and organizations provide information and news, mostly focusing on events and issues that are not reported or misreported in the mainstream media. The primary use of the Internet in online advocacy is to organize movements and take action. The internet is primarily to organize actions that allow a large number of groups of activists and individual protesters involved to establish efficient communication channels. Informal social networks embedded in the internet and social media are one of the most important sources for mobilizing individuals to join social movements [25]. Thus, the internet is used for mobilization in two different ways. First, it used to call for action, established mobilization of people. Second, it used to demand actions that normally occur offline, therefore performed more efficiently online.

\section{Conclusion}

The civil society in Indonesia playing an active role in the humanitarian narrative spreading the information that could result in humanitarian responses. They generally spread information through the internet/ media social and providing for people to organize activities such as humanitarian aid and humanitarian actions. In addition, it would support the organization and NGOs to develop their strategy and planning for humanitarian aid and humanitarian actions. Civil society as an actor establishes collective action in certain public spaces to express interests, desires, and ideas. At the same time, the exchange of information in technological developments forces the community to achieve collective goals for a local and global community order. New technology has facilitated new types of communication and civil society engagement, creating an opening for the participation of more people in one platform, cyberspace.

\section{References}

[1] World Economic Forum, “The Future Role of Civil Society,” World Scenar. Ser., no. January, 2013.

[2] P. Hallikainen, "Why People Use Social Media Platforms: Exploring the Motivations and Consequences of Use," From Inf. to Smart Soc., vol. 5, pp. 9-16, 2015.

[3] G. T. Mitoma, "Civil society and international human rights: The commission to study the organization of peace and the origins of the UN human rights regime," Hum. Rights Q., vol. 30, no. 3, pp. 607-630, 2008.

[4] S. Peberdy and M. K. Jara, "Humanitarian and social mobilization in Cape Town: Civil society and the May 2008 xenophobic violence," Politikon, vol. 38, no. 1, pp. 37-57, 2011.

[5] D. Lewis, "Humanitarianism, civil society and the Rohingya refugee crisis in Bangladesh," Third World Q., vol. 40, no. 10, pp. 1884-1902, 2019.

[6] K. Virk and F. Nganje, "The Peacebuilding Role of Civil Society in South Sudan," 2016.

[7] C. Sperfeldt and J. Oeung, "The evolution of Cambodian civil society's involvement with victim participation at the Khmer Rouge trials," in Civil Society and Transitional Justice in Asia and the 
Pacific, L. KENT, J. WALLIS, and C. CRONIN, Eds. ANU Press, 2019, pp. 85-105.

[8] J. Rose, P. O'Keefe, J. Jayawickrama, and G. O’Brien, “The challenge of humanitarian aid: An overview," Environmental Hazards, vol. 12, no. 1. pp. 74-92, 2013.

[9] C. Malena and V. F. Heinrich, "Can we measure civil society? A proposed methodology for international comparative research," Dev. Pract., vol. 17, no. 3, pp. 338-352, 2007.

[10] R. Marchetti, "Civil society, global governance, and the quest for legitimacy," Glob. Multilater. Eur. Towar. a Better Glob. Governance?, no. January 2016, pp. 301-315, 2016.

[11] C. Barnes, "Civil society and peacebuilding: Mapping functions in working for peace?," Int. Spect., vol. 44, no. 1, pp. 131-147, 2009.

[12] R. Blaug and J. Schwarzmantel, 75. Networks of Outrage and Hope: Social Movements in the Internet Age. Cambridge: Polity Press, 2017.

[13] D. T. Hill and K. Sen, Media, Culture and Politics in Indonesia. 2000.

[14] M. Lim, "The Internet, Social Networks , and Reform in Indonesia The Internet: A Convivial Medium for Civil Society," pp. 273-288, 2004.

[15] J. Y. Hui, "The internet in Indonesia: Development and impact of radical websites," Stud. Confl. Terror., vol. 33, no. 2, pp. 171-191, 2010.

[16] APJII, "Penetrasi \& Profil Perilaku Pengguna Internet Indonesia," Asos. Penyelenggara Jasa Internet Indones., 2018.

[17] Kementerian Luar Negeri, "Humanitarian Issues | Portal Kementerian Luar Negeri Republik Indonesia," 2019. .

[18] T. Gruenewald and S. Witteborn, "Feeling good: humanitarian virtual reality film, emotional style and global citizenship," Cult. Stud., vol. 2386, no. May, 2020.

[19] Suaka, "Refugees and asylum seekers in indonesia.," Suaka: Indonesian Civil Society Association for Refugee Rights Protection, 2019.

[20] R. W. Cox, "Social forces, states and world orders: beyond international relations theory," Millennium, vol. 10, no. 2, pp. 126-155, 1981.

[21] R. Little, Perspectives on World Politics. 2005.

[22] M. M. Skoric, Q. Zhu, D. Goh, and N. Pang, "Social media and citizen engagement: A metaanalytic review," New Media Soc., vol. 18, no. 9, pp. 1817-1839, 2016.

[23] H. Haaland and H. Wallevik, "Beyond crisis management? The role of Citizen Initiatives for Global Solidarity in humanitarian aid_the case of Lesvos," Third World Q., vol. 40, no. 10, pp. 1869-1883, 2019.

[24] S. Vegh, "Classifying forms of online activism: The case of cyberprotests against the World Bank," Cyberactivism Online Act. theory Pract. Ed. by McCaughey, M. Ayers, M. D. 71-95. London Routledge., 2003.

[25] Z. Tufekci, “'Not This One': Social Movements, the Attention Economy, and Microcelebrity Networked Activism," Am. Behav. Sci., vol. 57, no. 7, pp. 848-870, 2013. 